\title{
Rancang Bangun Alat Penyiram Tanaman Kentang Gantung Otomatis Berbasis Arduino
}

\author{
Badie Uddin ${ }^{1}$; Muhammad Zaky Firmansyah ${ }^{2}$; Shelvie Nidya Neyman ${ }^{3}$; Sri Wahjuni ${ }^{4}$; \\ Heru Sukoco ; Hendra Rahmawan ${ }^{6}$ \\ 1, 3, 4, 5, 6 Department of Computer Science, Bogor Agricultural University, Indonesia \\ ${ }^{2}$ Department of Computer Engineering, TEDC Polytechnic, Indonesia \\ ${ }^{1}$ badie.uddin@gmail.com \\ 2zakyf16@gmail.com \\ ${ }^{3}$ shelvie@apps.ipb.ac.id \\ ${ }^{4}$ my_juni04@apps.ipb.ac.id \\ ${ }^{5}$ hsrkom@apps.ipb.ac.id \\ ${ }^{6}$ hrahmawan@apps.ipb.ac.id
}

\begin{abstract}
Watering plants for hanging potato seedlings at the Balai Penelitian Tanaman Sayuran (Balitsa) Lembang, West Bandung, when this paper was written still uses a manual water spray tool and requires quite a long time. Not only the time constraint when watering, the temperature of the room where the plant is a problem for these hanging potato plants, because the temperature is very influential on the growth of hanging potatoes. Hanging potato sprinklers built using Arduino Uno as a microcontroller and supported by the Arduino IDE application. This sprinkler is also equipped with DS18B80 as a temperature sensor, where the DS18B20 interface uses only one cable as communication (using the Unique 1-Wire protocol). Each sensor has a unique 64-bit identification code embedded in the onboard ROM. The DS18B20 is able to measure temperatures from $-55^{\circ} \mathrm{C}$ to $+125^{\circ} \mathrm{C}$ with an accuracy of $+/-0.5^{\circ} \mathrm{C}$ in the range of $-10^{\circ} \mathrm{C}$ to $+85^{\circ} \mathrm{C}$ and can convert temperature data to 12-bit digital words in only 750 milliseconds (maximum). Watering is focused on the roots of potatoes, in 1 day carried out several times automatic watering in accordance with a predetermined temperature. If the temperature reaches $26^{\circ} \mathrm{C}$, the appliance will be ON, but when the temperature is below $24^{\circ} \mathrm{C}$, the appliance is automatically turned OFF. The remaining water from the watering will be collected, then flowed back to the water storage tube that will be used to do the watering again. Growing media used for hanging potato plants are aeroponics, this is intended so that plants are not susceptible to disease.-alone. Reference, non-standard or uncommon abbreviation should be avoided in the abstract.
\end{abstract}

Keywords: Balitsa, Watering plants, Hanging Potato, Arduino, Automatic

\section{ABSTRAK}

Penyiram tanaman untuk bibit kentang gantung di Balai Penelitian Tanaman Sayuran (Balitsa) Lembang Kabupaten Bandung Barat saat paper ini ditulis masih menggunakan alat semprot air secara manual dan memerlukan waktu yang cukup lama. Tidak hanya kendala waktu saat penyiraman, suhu ruang tempat tanamanpun menjadi permasalahan untuk tanaman kentang gantung ini, karena suhu tersebut sangat berpengaruh terhadap pertumbuhan kentang gantung.

Alat penyiram tanaman kentang gantung yang dibangun menggunakan Arduino Uno sebagai mikrokontroler dan didukung oleh aplikasi Arduino IDE. Alat penyiram ini dilengkapi juga dengan DS18B80 sebagai sensor suhu,.dimana antarmuka DS18B20 hanya menggunakan satu kabel sebagai komunikasi (menggunakan protokol Unique 1-Wire).Setiap sensor memiliki kode pengenal unik 64-bit yang tertanam di onboard ROM. DS18B20 ini mampu mengukur temperatur mulai dari $-55^{\circ} \mathrm{C}$ hingga $+125{ }^{\circ} \mathrm{C}$ dengan akurasi $+/-0.5{ }^{\circ} \mathrm{C}$ pada rentang $-10{ }^{\circ} \mathrm{C}$ hingga $+85{ }^{\circ} \mathrm{C}$ serta bisa mengkonversi data suhu ke 12-bit digital word hanya dalam 750 milidetik (maksimal). Penyiraman air difokuskan pada akar kentang, dalam 1 hari dilakukan beberapa kali penyiraman secara 
PETIR: Jurnal Pengkajian dan Penerapan Teknik Informatika

Vol. 14, No. 1, Maret 2021, P-ISSN 1978-9262, E-ISSN 2655-5018

DOI: https://doi.org/10.33322/petir.v14i1.1108

otomatis sesuai dengan suhu yang telah ditentukan. Jika suhu mencapai $26{ }^{\circ} \mathrm{C}$ maka alat akan ON namun pada saat suhu di bawah $24^{\circ} \mathrm{C}$ alat otomastis dalam kondisi OFF. Sisa air dari peryiraman tersebut akan ditampung, lalu dialirkan kembali pada tabung penyimpanan air yang akan digunakan untuk melakukan penyiraman lagi. Media tumbuh yang digunakan untuk tanaman kentang gantung ini yaitu aeroponik, hal ini dimaksudkan agar tanaman tidak mudah terserang penyakit.

Kata kunci: Balitsa, Penyiram Tanaman, Kentang Gantung, Arduino, Otomatis 


\section{PENDAHULUAN}

Kentang (Solanum tuberosum L) adalah tanaman umbi-umbian yang merupakan makanan pokok di Eropa, walaupun pada awalnya didatangkan dari Amerika Selatan. Kentang merupakan tanaman dari suku Solanaceae yang memiliki umbi batang yang dapat dikonsumsi. Untuk daerah tropis seperti Indonesia, kentang sangat cocok ditanam di dataran tinggi karena mempunyai iklim yang sejuk.

Saat ini di Balai Penelitian Tanaman Sayuran (Balitsa) Lembang Kabupaten Bandung Barat penyiram tanaman untuk bibit kentang gantung masih menggunakan alat semprot air yang dilakukan secara manual dan memerlukan waktu yang cukup lama, hal ini kurang efektif, karena di Balitsa tidak hanya melakukan penelitian tanaman sayuran tetapi juga dilakukan pembudidayaan tanaman sayuran untuk dijual ke masyarakat. Diperlukan sumberdaya untuk mengatasi permasalahan ini, karena tidak hanya permasalahan efektifitas waktu penyiraman namun kondisi suhu di dalam ruang tempat penyiram tanaman juga sangat berpengaruh bagi tanaman untuk tumbuh.

\section{PERANCANGAN PENELITIAN}

\subsection{Analisis Sistem yang Berjalan}

Hasil analisis dan observasi secara langsung penulis di Balitsa, terdapat beberapa kelemahan pada alat penyiram tanaman kentang gantung yaitu waktu penyiraman tanaman kentang di-set secara manual selama 2 menit (ON) dan alat akan mati (OFF) selama 15 menit. Alat inipun tidak dilengkapi dengan pengatur (sensor) suhu, sehingga tidak dapat memastikan kondisi suhu ruang tempat penyiram tanaman kentang. Berikut adalah gambar dari alat penyiram tanaman kentang gantung yang digunakan di Balitsa:
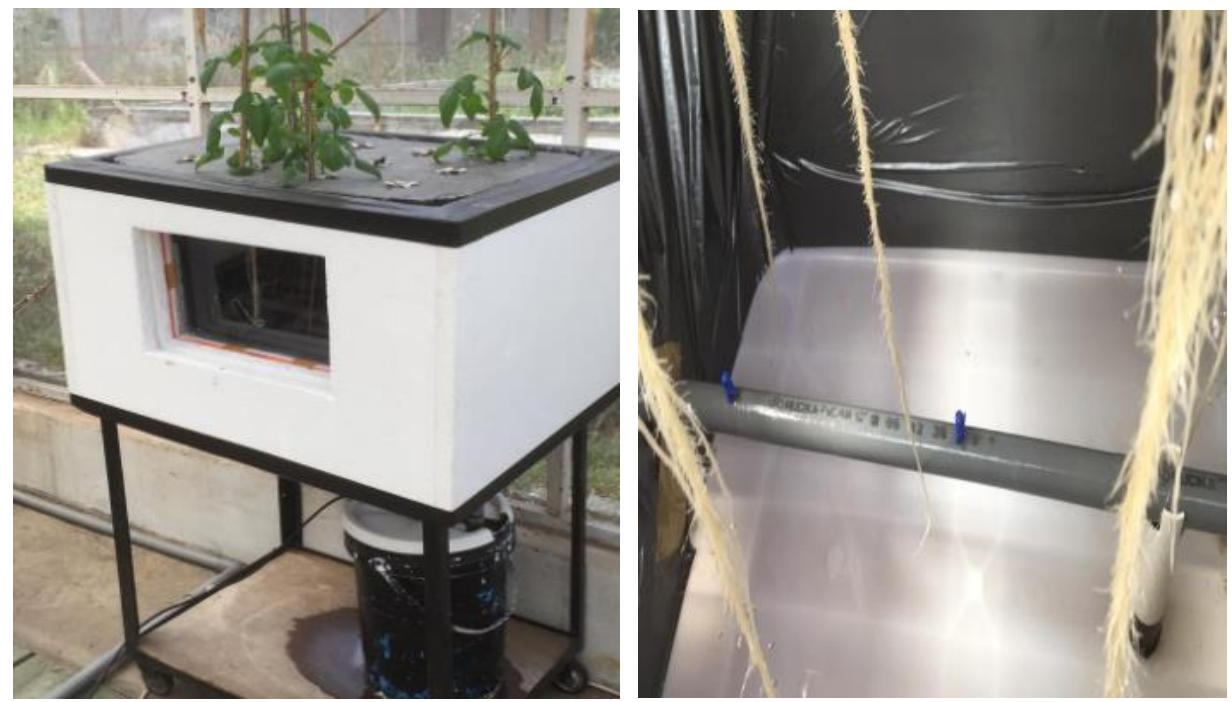

Gambar 1. Alat penyiram kentang gantung 


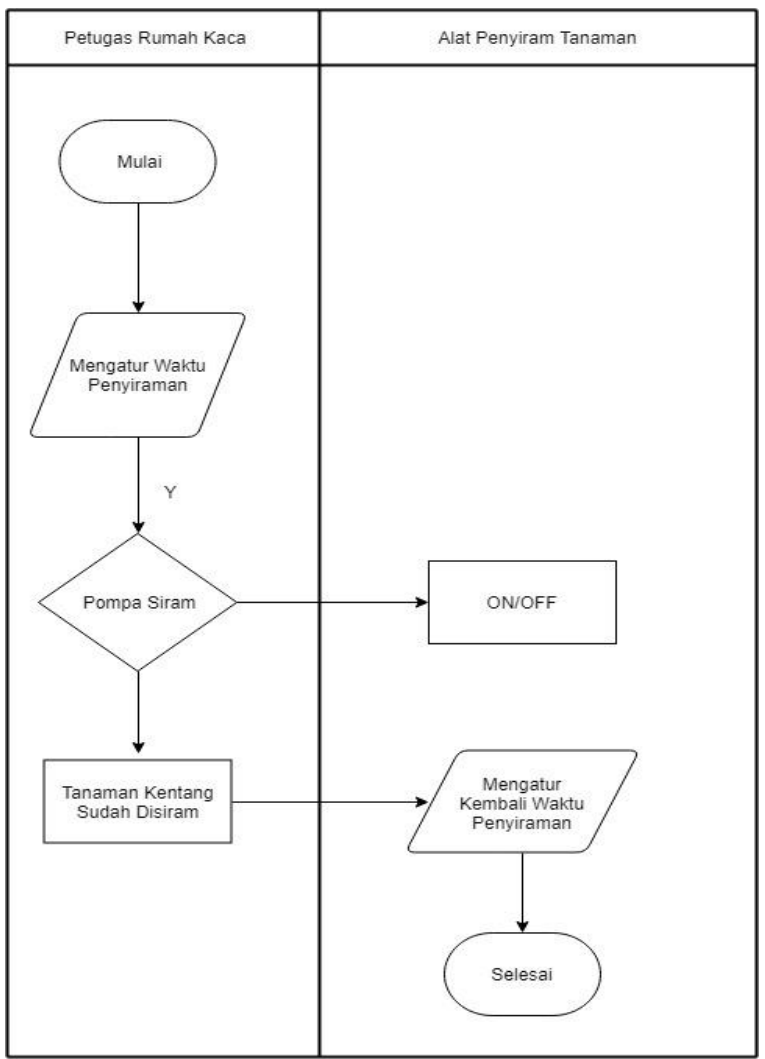

Gambar 2. Flowmap Sistem yang berjalan

\subsection{Analisis Sistem yang akan Dirancang}

Perancangan alat penyiraman kentang otomatis ini berbasis Arduino dilengkapi dengan sensor agar alat dapat bekerja secara optimal. Berikut blok diagram dan flowmap perancangan alat penyiraman kentang otomatis berbasis Arduino yang akan dibangun.

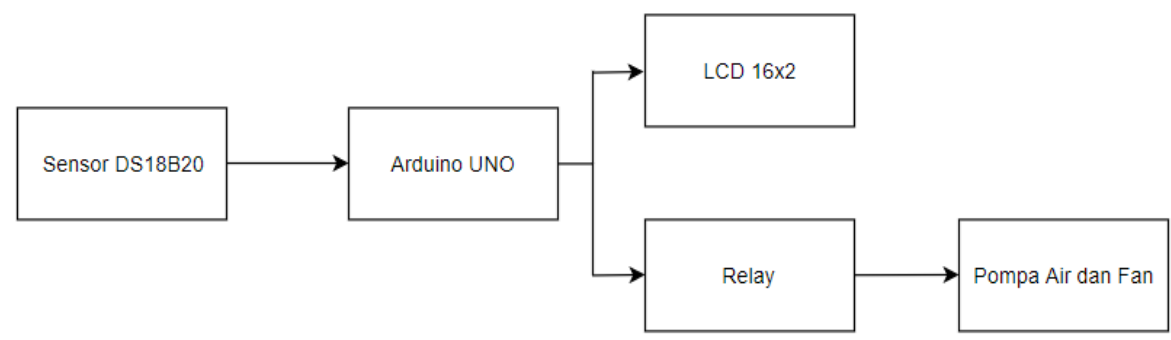

Gambar 3. Blok diagram yang akan dirancang 


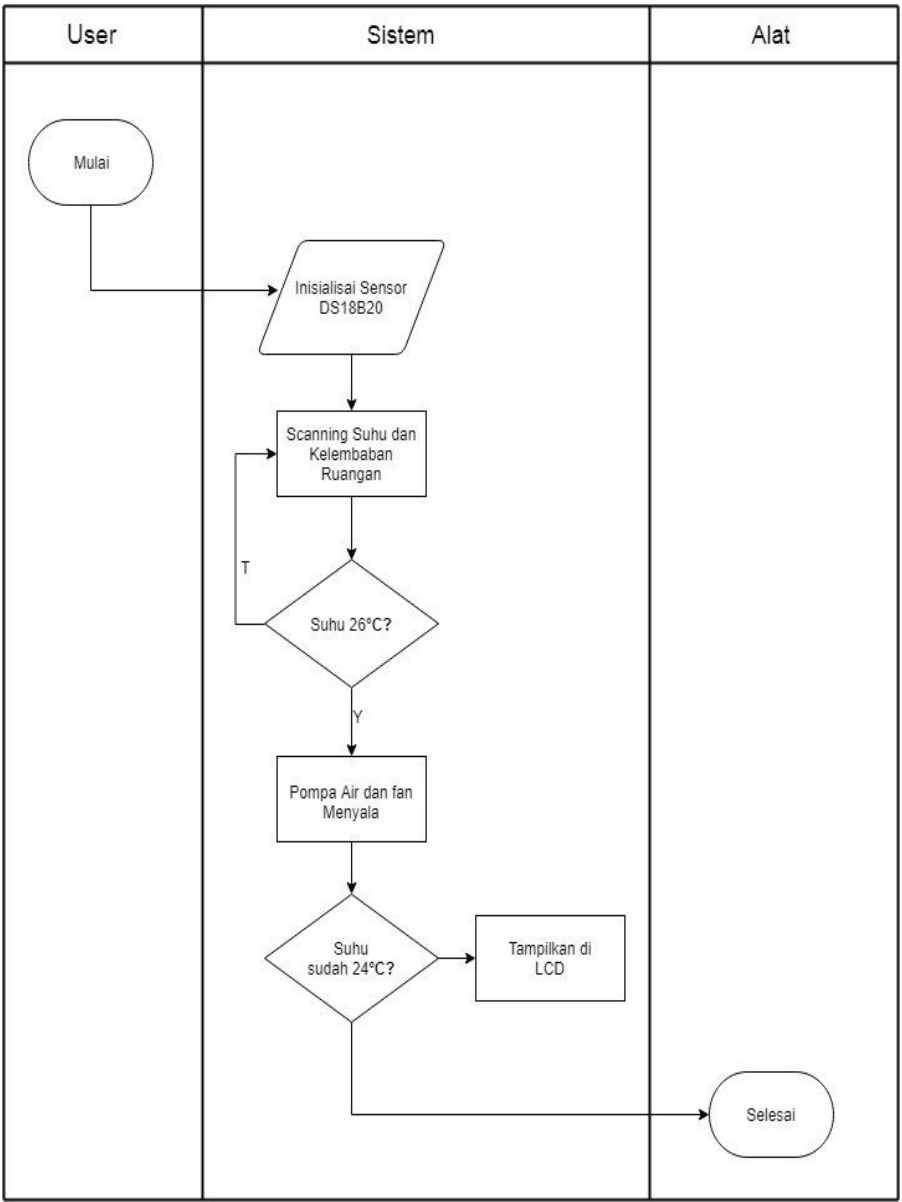

Gambar 4. Flowmap alat yang akan dirancang

\subsection{Skema Rancangan Perangkat Keras}

Beberapa pin mikrokontroler Arduino Uno saling dihubungkan dengan pin pada komponen lain agar saling berkomunikasi dan memberikan respon. Tidak semua pin dari Arduino Uno yang akan dipakai, hanya ada beberapa pin yang dibutuhkan untuk dihubungkan dengan perangkat lain.

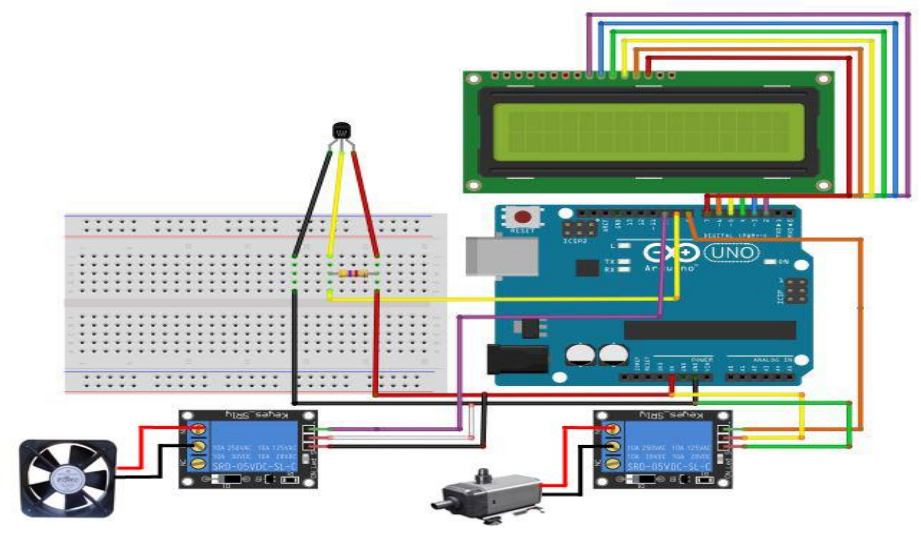

Gambar 5. Skema rancagan perangkat keras 


\subsection{Modeling Alat Yang Dikembangkan}

Modeling alat yang akan dikembangkan ini adalah gambaran alat yang akan dirancang. Berikut ini adalah perancangan alat penyiram tanaman kentang otomatis yang akan penulis buat.

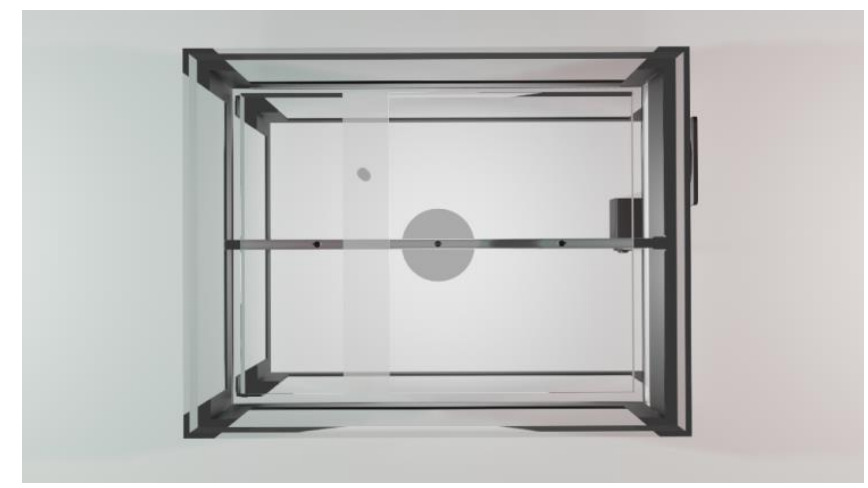

Gambar 6. Tampilan modeling alat bagian atas

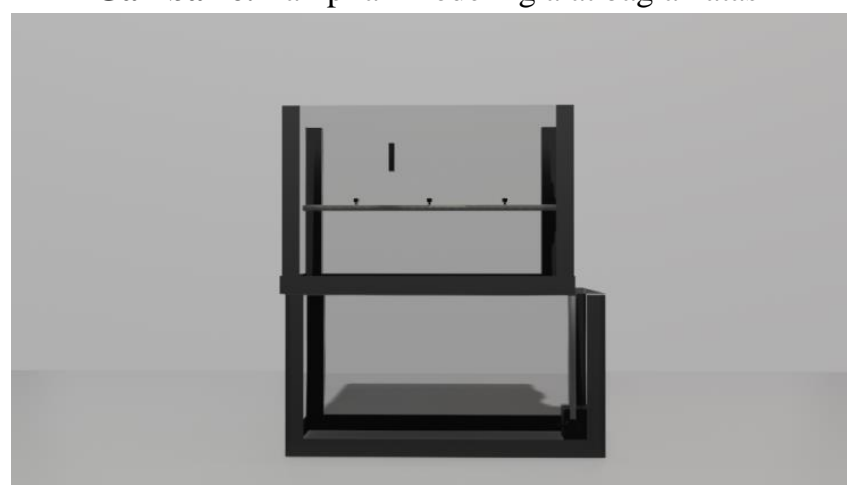

Gambar 7. Tampilan modeling alat bagian samping

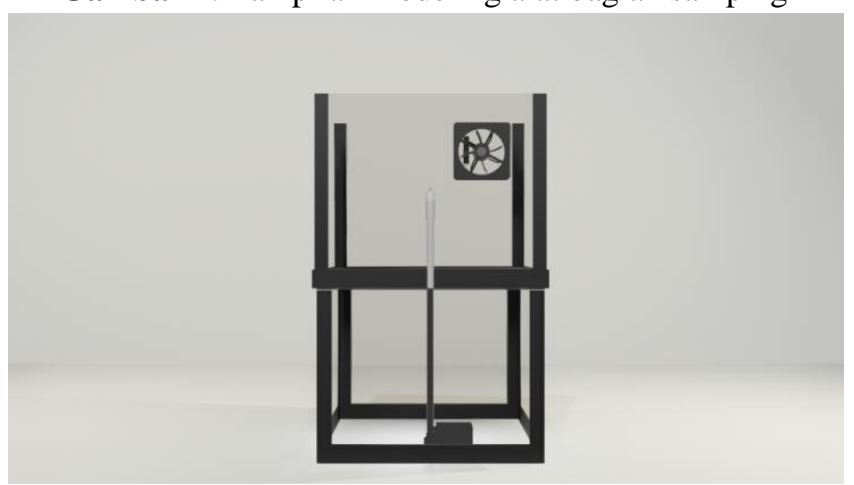

Gambar 8. Tampilan modeling alat bagian belakang

Perancangan alat penyiram tanaman kentang otomatis ini akan diberi tempat penyimpanan, untuk sensor DS18B20 akan ditempatkan dibagian atas, pompa air akan ditempatkan dibawah bagian kanan, dan pipa air yang tersambung dengan pompa air akan mengarah ke atas dan akan menggunakan sambungan pipa untuk mengarah ke kiri. Pipa air akan dilengkapi 3 buah springkler dan juga dilengkapi dengan sebuah fan (kipas) untuk menurunkan suhu. Modeling yang akan dibuat dilengkapi sumur resapan yang bertujuan untuk mengalirkan kembali air penyiraman agar bisa dipakai menyiram lagi.

Perancangan alat ini menggunakan bahan Akrilik, dengan kotak persegi panjang. Kotak persegi panjang bagian atas untuk peyimpanan tanaman kentang. Sedangkan kotak persegi panjang 
bagian bawah untuk tempat penyimpanan dan penampungan air dari alat penyiraman tanaman kentang otomatis

\section{HASIL DAN PEMBAHASAN}

Pengujian bertujuan untuk menemukan kesalahan dan kekurangan pada alat yang sudah dibuat, apakah sistem yang dibangun sudah sesuai dengan perancangan yang telah dibuat atau belum. Pengujian yang dilakukan adalah untuk mengetahui apakah pompa air dan kipas angin (fan) akan menyala pada suhu 26 derajat celcius dan melakukan penyiraman dan pompa air dan fan akan mati setelah pada suhu 24 derajat celcius. Pengujian ini dilakukan untuk mengetahui apakah alat penyiraman akan menyala dan mati secara otomatis dengan suhu yang telah ditentukan.

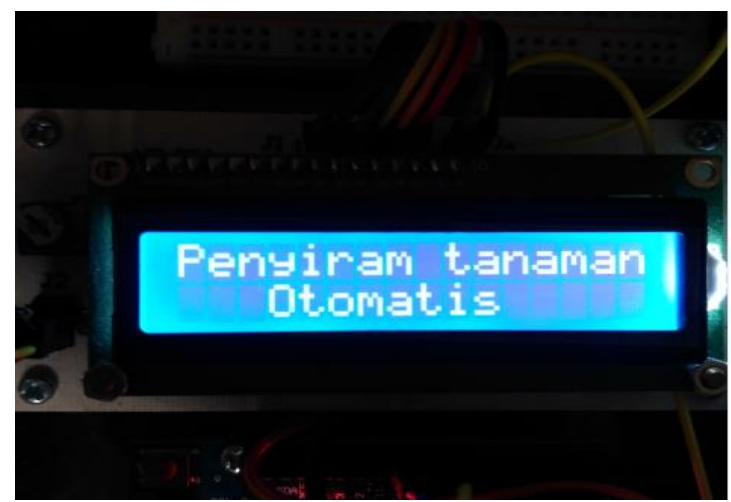

Gambar 9. Tampilan LCD saat alat pertama kali dinyalakan

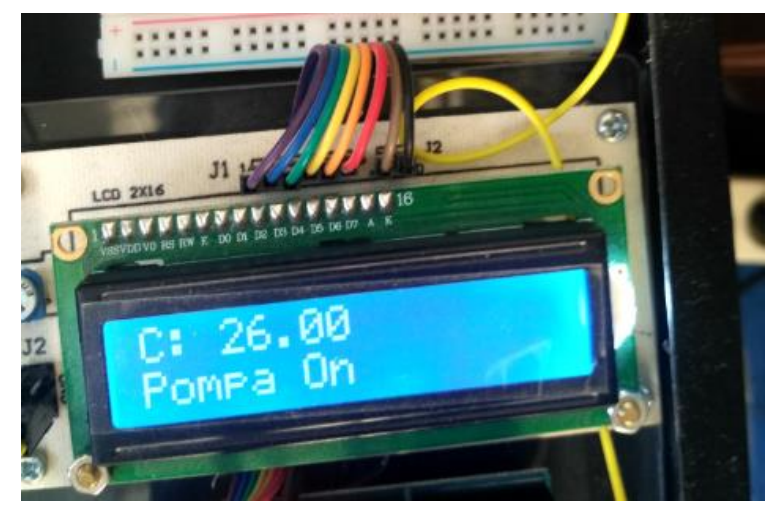

Gambar 10. Alat penyiram $O n$

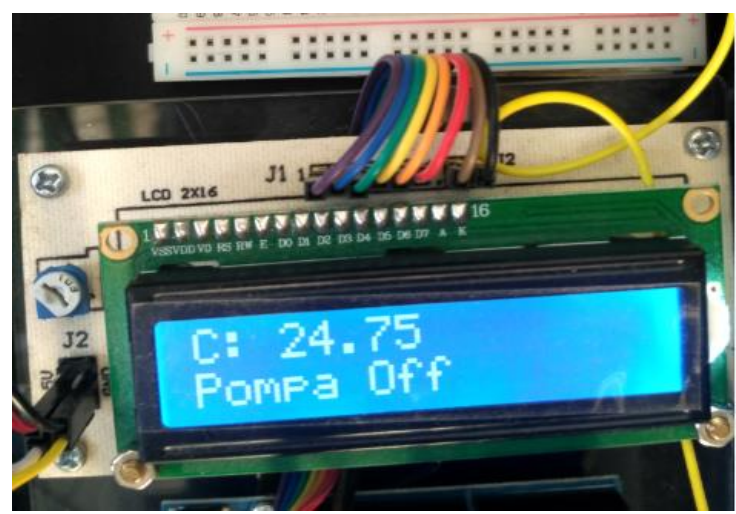

Gambar 11. Alat penyiram $O f f$ 
Tabel 1. Hasil pengujian alat

\begin{tabular}{|c|l|c|}
\hline No & \multicolumn{1}{|c|}{ Fungsi } & Hasil \\
\hline 1. & $\begin{array}{l}\text { Ketika suhu mencapai 24 derajat celcius } \\
\text { pompa air dan fan menyala secara otomatis }\end{array}$ & $\begin{array}{c}\text { Berfungsi } \\
\text { dengan Baik }\end{array}$ \\
\hline 2. & $\begin{array}{l}\text { Ketika suhu mencapai 24 derajat celcius } \\
\text { pompa air dan fan mati secara otomatis }\end{array}$ & $\begin{array}{c}\text { Berfungsi } \\
\text { dengan Baik }\end{array}$ \\
\hline 3. & $\begin{array}{l}\text { Sensor akan terus memonitor suhu setelah } \\
\text { kondisi alat sedang off dan akan on jika } \\
\text { suhu kembali naik menjadi 26 derajat } \\
\text { celcius }\end{array}$ & $\begin{array}{c}\text { Berfungsi } \\
\text { dengan Baik }\end{array}$ \\
\hline 4. & $\begin{array}{l}\text { LCD menampilkan nilai suhu di dalam alat } \\
\text { penyiram tanaman }\end{array}$ & $\begin{array}{c}\text { Berfungsi } \\
\text { dengan Baik }\end{array}$ \\
\hline
\end{tabular}

Dari tabel di atas dapat dilihat bahwa semua komponen pada alat penyiram tanaman dapat berfungsi dengan baik sesuai dengan tujuan perancangan alat penyiraman tanaman otomatis.

\section{KESIMPULAN DAN SARAN}

Rancang Bangun Alat Penyiram Tanaman Kentang Gantung ini dilengkapi Sensor DS18B20, sensor ini berfungsi dengan baik ditunjukan dengan tampilan pada display (LCD). Relay berfungsi dengan baik ditunjukan dengan berfungsinya alat pompa penyiram air dan fan (kipas). Pompa air dan fan berfungsi dengan baik, untuk menyiram akar tanaman kentang yang menggantung di dalam ruang penyiraman dan dapat menurunkan suhu ruangan tempat akar, sehingga waktu penyiraman pada alat ini dapat berfungsi berdasarkan suhu yang telah ditentukan.

Beberapa saran untuk pengembangan alat penyiram tanaman ini yaitu perlu menambahkan sistem (modul) yang dapat mengubah waktu penyiraman berdasarkan suhu apabila suhu yang diperlukan pada saat melakukan penyiraman ingin diubah (adjustment).

\section{UCAPAN TERIMAKASIH}

Penulis mengucapkan terima kasih kepada Bapak Gunawan sebagai Koordinator Perlengkapan Rumah Tangga dan Bapak Usep Jaenudin sebagai teknisi Penelitian dan Perekayasaan (Litkayasa) Pemuliaan dan Pembenihan di Balai Penelitian Tanaman Sayuran (Balitsa) Lembang Kabupaten Bandung Barat yang telah menyediakan tempat, sarana dan prasarana dalam melaksanakan penelitian.

\section{DAFTAR PUSTAKA}

[1] Yudika Pratamanda1, Dr. Ismudiati Puri Handayani, S.Si., M. Sc., Ahmad Qurthobi, M. T. Pengaruh Pengkondisian Temperatur Pada Produksi Benih Kentang Menggunakan Sistem Aeroponik, Universitas Telkom.2017.

[2] Putri Sekar Ayu Dutaning Pratiwi, Citra Kurniawan. Rancang Bangun Penyiram Tanaman Stroberi Otomatis Menggunakan Arduino Uno, Sekolah Tinggi Teknik Malang.2018

[3] Rangga Zainal Muttaqin. Sistem Informasi Tata Administrasi Laboratorium Di Balai Penelitian Tanaman Sayuran Cikole - Lembang.STMIK“AMIKBANDUNG”.2014

[4] Prinsip Kerja Pompa Air https://www.wikikomponen.com/prinsip-dan-cara-kerja-mesinpompa-air/Diakses Pada Tanggal : 28 Desember 2019 
[5] Penyiram Tanaman Otomatis http://belajarmikrokontroler2017.blogspot.com/2018/02/penyiram-tanaman-otomatis-berdasarkan.html Diakses Pada Tanggal : 28 Desember 2019

[6] Sistem Aeroponik http://taman-berkebun.blogspot.com/2015/09/sistem-aeroponikhidroponik.html Diakses Pada Tanggal : 3 Januari 2019

[7] Pengertian Tanaman Kentang http://duniaplant.blogspot.com/2015/04/definisi-tanamankentang-dan.html Diakses Pada Tanggal : 15 Januari 2020 